\title{
Criteria and Factors Affecting Sustainable Housing Design in Iran
}

\author{
Davood Baradaran Tavakoli ${ }^{1}$, Maryam Tafrishi ${ }^{2} \&$ Ehsan Abbaspour ${ }^{1}$ \\ ${ }^{1}$ College of Art and Architecture, Mashhad Branch, Islamic Azad University, Iran \\ ${ }^{2}$ Department of Art and Architecture, Shiraz Branch, Islamic Azad University, Fars, Iran \\ Correspondence: Davood Baradaran Tavakoli, Ph.D. Student of Architecture, College of Art and Architecture, \\ Mashhad Branch, Islamic Azad University, Iran. Tel: 98-930-470-1725. E-mail: davoodbaradaran@mshdiau.ac.ir
}

Received: March 23, 2017

doi:10.5539/jsd.v10n3p194
Accepted: May 2, 2017 Online Published: May 31, 2017

URL: https://doi.org/10.5539/jsd.v10n3p194

\begin{abstract}
Since the beginning of human life, housing problems are the most important matters of his life and with the expansion of urban life, importance in terms of the needs of mental, psychological and physical users has been doubled. The housing subject has been always interest to architects from various aspects and attempts made to improve affordable housing, attempts to improve relations or social housing, or seek to identify and develop the cultural origins, economics, management and other macro policies. On the other hand due to the growing population and consequently expand need to housing, and also identifying of residential needs of people in different dimensions necessity of this research is doubled. This study assuming more than half of the land in our cities is devoted to residential use and also lack of attention to sustainable development in the Residential Buildings the purpose of this study sustainable urban development and the achievement of sustainable affordable housin pattern.

This study focuse on descriptive- analytical and based on library research seeks to answer this question: What are the criteria for designing sustainable housing in Iran? Thus, after the introduction, do analysis and commentary related content. Conclusion suggest that in addition to aspects of sustainability (economic, social and environmental), factors such as social, cultural and attention to the flexibility according to Iranian households, design sustainable housing should be considered.
\end{abstract}

Keywords: housing, sustainability, culture, flexibility, pattern

\section{Introdution}

In Iranian architecture, valuable methods and strategies have always been proposed to provide proper living conditions in buildings. Variety of different that have driven architects to employ innovative principles in order to provide the best and most appropriate ways of adapting to climate and proper use of climatic conditions. Today, these principles and patterns by proper integration with new technologies can be fitted into contemporary architectural structures and with its own identity provide new and stable architecture. Examining the valuable works of Iranian architects in this vast territory and on different scales signifies a comprehensive and objective way of thinking in the use of different buildings. This way of thinking identifies the appropriate use and blend of contemporary architectural principles and results in improving these architectural styles(Molanaei, S \& Soleimani, S, 2016).

Architectural design as a solution that aims to create a safe shelter against natural hazards has attracted people's attention since the beginning of history(Mahmoudi, 2008: 97).

Since the beginning of human life, housing problems are the most important matters of his life and with the expansion of urban life, importance in terms of the needs of mental, psychological and physical users has been doubled. There are various aspect in context of sustainable housing which each of them are subject specific parameters in the design. Many of them have variety of construction methods, and pays to economic topics, social and political and technical housing(Edwards B, Torrent D, 2015).

Although achieving sustainable development rather than on technical factors, is a cultural matter. Sustainable housing is influenced by the consumer and not uncertainties and technical uncertainty achieved. Some believes which eighty percent of resistance stability on cultural factors and only twenty percent on technical factors. Although these quantities may seem a bit exaggerated but it is clear that if sustainable design is to become main 
topic, it is necessary to consider the consumer status and conditions(Edwards B, Torrent D, 2015). One hand attention to the growing population and consequently need to the wider housing and on the other hand understanding the residential needs people in social, cultural and economic, provides the necessity of this research.

This study seeks to achieve goals such as creation of affordable housing pattern accordance with needs and conditions of the users, creation of psychological and thermal comfort, health and as well as ability to set and adapt residential units over time with the demands of the residents versatility, this means that with the ability to change the size and create open spaces and private spaces without reduction and converting them into public spaces in the home is the comfort and efficiency enhance the spaces. In this way we analysis and commentary content extend to achieve acceptable results.

\section{Literature Review}

In order to present the current theories related to energy consumption and saving in indigenous housing and texture, some of points of views and ideas are discussed:

Jalalian and Tahbaz, in their article named "saving energy consumption in rural housing of Dasht-e-Moghan", apart from recognizing and analyzing indigenous architecture of the region, the current ways in construction and examples of sustainable architecture and architectural solutions have been gathered.

Also, Zandiyeh and Parvardinejad, in their article, "sustainable development and its concepts in Iran's residential architecture" presented the climatic techniques in Iranian housing and resulted that vernacular architecture would be a proper pattern for current architecture.

Finally, Khodabakhshi and Mofidi, in their research named "sustainable construction related in Iran's vernacular architecture" after reviewing previous researches, gathered all theories and studies and analyzed vernacular features in four distinct climates with respect to case studies(Sargazi, MA, 2014)

In this study, theoretical research in the form of descriptive principles offer that includes sustainability, culture, flexibility and finally Provide optimal patterns for sustainable housing in Iran.

\subsection{Sustainability}

In the McGraw-Hill Dictionary of Scientific and Technical Terms (2003), the term "Sustainable Development" is defined as developing natural and industrial resources that meet the energy needs of the current times without settling the ability of next generations for meeting their needs in the same manner. In addition, the United Nations (1987) explains that: Sustainable development is collection of methods to create and sustain development which seeks to relieve poverty, create equitable standards of living, satisfy the basic needs of all peoples, and establish sustainable political practices all while taking the steps necessary to avoid irreversible damages to natural capital in the long term in turn for short term benefits by reconciling development project with the regenerative capacity of the natural environment(Samari, M, 2012)

At the level of the dictionary definition, sustainability simply implies that a given activity or action is capable of being sustained (i.e. continued indefinitely). Within the environmental domain, this is not particularly helpful since many highly damaging practices can be sustained within time frames that, relative to the individual human life span, and certainly the cycles of corporate profit-taking, are seemingly indefinite. Many people, indeed, argue that ecosystems will in time adapt to the changes we inflict upon them; a perverse depiction of a sustainable future world but one to which some nonetheless cling tenaciously(Johnston, paul \& others, 2007)

There are many features of sustainable development among these are;

- Environment - The development of truly taking by human activities on the environment and health. - Social Equality - Development that contributes to the acquisition and control of a more appropriate source.

- Human Economics - Social and economic development to help people meet basic needs.

- The Future - Ensure that the decision taken not to damage or prejudice the interests of future generations.

- Participation - The process that allows the entire community involved.

- Local Action / Global Impact - Local development that contributes to the resolution of global issues. In conclusion, the principles of sustainable housing can be defined as a way of creation and the management responsible for achieving a healthy development(Abd, R \& Arkam che munaaim, M, 2013). 


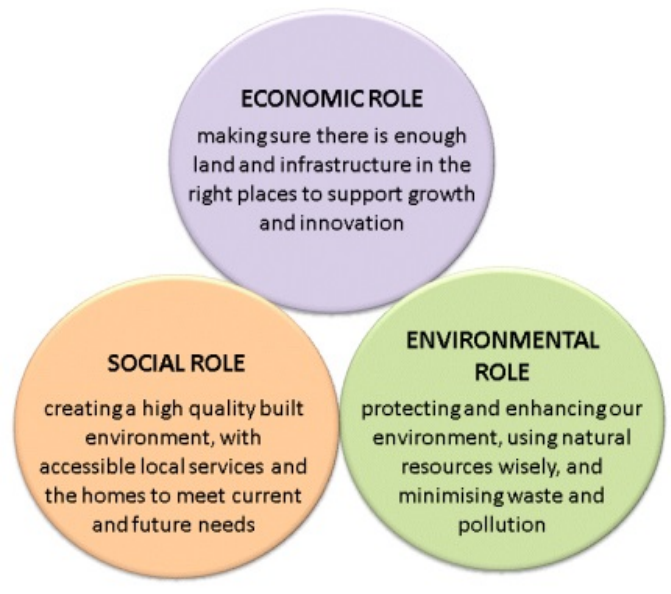

Figure 1. Importance of housing in creating stable communities (URL1)

\subsection{Sustainable Housing}

The principle of sustainable housing is to give comfort and safety in human lives (Fig. 2). The application of this principle occurs directly and indirectly recognized by the owner or not. The principles applied in sustainable housing, including concern for people by ensuring that they live in a healthy, productive and in harmony with nature(Nazirah, Z. A. dan P, 2005). This principle needs to give priority to the interests of future generations without compromising the needs of the present generation(Abd, R \& Arkam che munaaim, M, 2013).

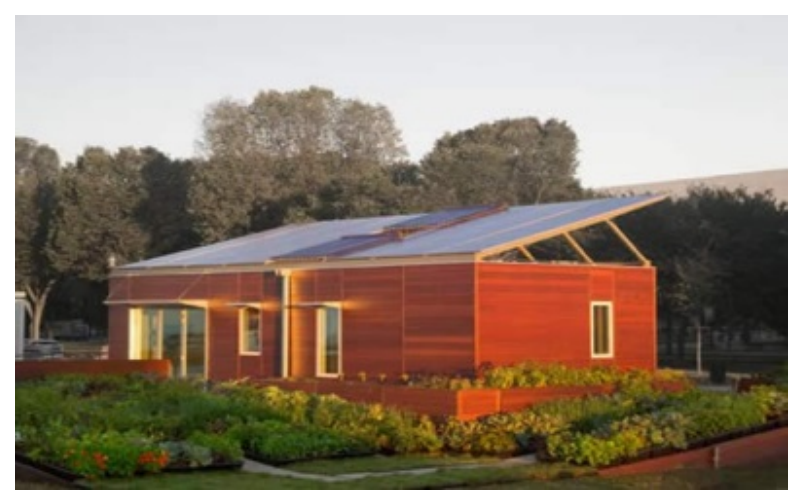

Figure 2. Sustainable housing(Abd, R \& Arkam che munaaim, M, 2013)

\subsection{Culture}

Since then, the relationship between culture and "arts and creativity" has been constantly negotiated challenging also the research and policy making(Pirnes, E, 2010). Travelling through the history of the concept of culture, Raymond Williams created three main meanings of culture that have become popular both in research and policy: culture as (1) a general process of intellectual, spiritual or aesthetic development; (2) a particular way of life, whether of a people, a period, a group, or humanity in general; and (3) works and intellectual artistic activity. Yet, very often two definitions of culture are discerned: a "broad", way-of-life based concept referring to all domains of human life, and a "narrow", art-based culture referring to both the general process of intellectual and spiritual or aesthetic development and its results (Pirnes, E, 2010, Williams, R, 1985). In the first representation ("culture in sustainability"), culture is seen as a general process of intellectual, spiritual or aesthetic development, as well as the results of intellectual and artistic work, which can also be called cultural capital in the Bourdieusian sense. The second representation "culture for sustainability" highlights culture as a way of life, referring to Williams' second meaning of culture: culture regulates all spheres of life, and reflects and gives meaning to the environment as well. The third representation ("culture as sustainability") opens up the broadest perspective for looking at human and social life as a whole. It is extending to semiosis and significations and their various influences both on intentional and unconscious behavior and functions over actions in human social life(Geertz, C, 1973). 
The first representation considers culture as if it had an independent role in sustainability: it becomes the fourth pillar of sustainability. This representation stands for culture in sustainability, and sees cultural sustainability as parallel to ecological, social, and economic sustainability(Soini, k \& Dessein, j, 2016).

\subsection{Flexibility}

According to the literature, there are few, if any, studies concerned with user assessment of preferred flexibility in house design. Notably, the assessment of flexibility in architectural design, as stated by (Veldhusien, K.J \& Others, 1987), is the most related to the user assessment of housing design(Veldhusien, K.J \& Others, 1987) considers a number of attributes for assessing the flexibility of architectural design. These attributes are the flexibility of the floor plan, the flexibility of the windows and doors, the finishes, the visibility of the service pipes, the sound level, and the cost to renovate. These assessment attributes are chosen by the researcher based on his predictions and findings(Lawson, B, 2004) posits that there are inherent differences in the methods by which a designer and a layperson evaluate and perceive living environment, where designer based on their knowledge. The evaluation given in the study by (Veldhusien, K.J \& Others, 1987) was conducted by laypersons but was based on the predictions of a researcher. The aforementioned studies, as well as others, are used to assess flexibility(Alaraji, KH \& Mohd jusan, M, 2014)

Flexibility is therefore ultimately tied into a sustainable social, environmental and economic imperative. Flexible housing, with the emphasis on technology (structure and services) and use, provides space for a degree of uncertainty in relation to the development of demographics, social relationships and technological progress. By acknowledging change as an underlying parameter but accepting the level and extent of change as unknown, flexibility is about the designing out of obsolescence and the future proofing of our buildings(Schneider, T \& Till, J, 2005).

\subsection{Flexible Housing}

Flexible housing means housing that can adapt to the changing needs of users. This implies that for housing to be flexible a number of principles should be addressed.

First, at the level of the building there should be flexibility between units, even to the extent of allowing change of use from residential. Second, individual units should be equipped, spatially as well as technically to be linkable or easily detachable, both vertically as well as horizontally, to allow for expansion or reduction of unit size. Thirdly, the interior layout of a unit either has to be adjustable to allow for different patterns of use (at the time of occupation, but also during occupation) or has to be designed in a way that does not predetermine its use(Schneider, T \& Till, J, 2005).

\subsection{Civil Rights}

In 1948, the United Nations in their Universal Declaration of Human Rights emphasized that 'everyone has the right to a standard of living adequate for the health and well-being of himself and of his family, including food, clothing, housing and medical care and necessary social services'(URL2). In 1966 about 18 years later, the United Nations General Assembly adopted Article 11 which provides the recognition of the 'right of everyone to an adequate standard of living for himself and his family, including adequate food, clothing and housing, and the improvement of living conditions'(URL3). Finally, in September 2000, the United Nations General Assembly presented eight principal goals, known as the Millennium Development Goals. Specifically, one of the targets within MDG Goal 7 calls for the global community to achieve a significant improvement in the lives of at least 100 million slum dwellers by 2020(URL4). Given that the latest estimate of the number of slum dwellers in the world is just under 1 billion(URL5), obviously even with the best intentions of the international community, $90 \%$ are expected to remain in housing that is over-crowded, unsafe, temporary, unhygienic, and very probably illegal even after 2020 and the conclusion of the Millennium Development Goals exercise( Choguill, CL, 2007). Hence, the issue of providing affordable, sustainable and decent housing for the low-income strata is considered as one of the emergent priorities of many governments throughout the world(Mahdavinejad, M \& Others, 2011).

\subsection{The Principles of Iranian Architecture}

According to Pirnia (2005), as a prominent scholar of traditional architecture of Iran, traditional architecture is based on five principles: (1)Introversion, (2)Autonomy, (3)Human- conformity, (4)Structure and Modulation, (5)Purposefulness(Pirnia, M, 2005). Fig.3 is a diagram which depicts these principles.

In traditional architecture of Iran and based on geographical location, bio-ecology, climate and by choosing a special roof type, the exposure of the exterior surface were reduced to direct sunlight, creating a shade in accordance with the climate of each region, wind catcher, cellar, central courtyard and windows facing the sun is faced to environment to gain the best comfort in interior spaces without making use of polluting facilities. In the 
other word, ancestors of this territory were completely aware of solar passive systems and always used this functional method(Kasmae, M, 2003). Besides, the performance and functional ability have been very important in designing and constructing the buildings. It has been tried to avoid creating unutilized space and in detail the whole space was engaged for special function. This subject even was followed in adornment and construction detail of buildings(Shahamat, H, 2014).
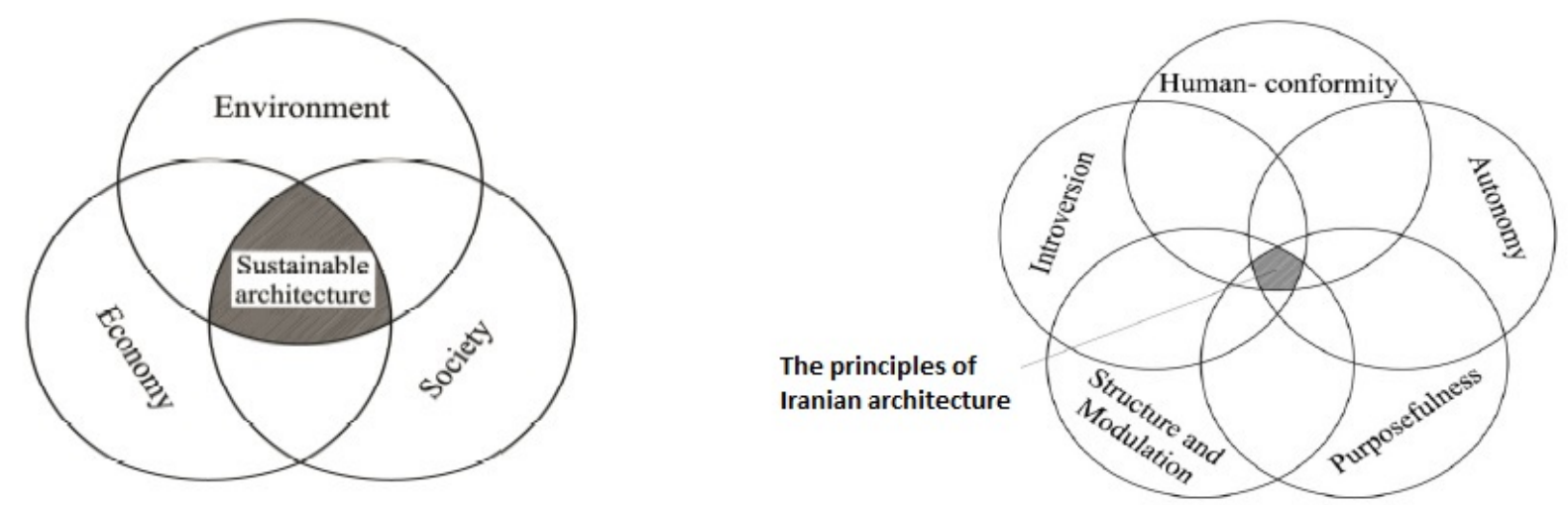

Figure 3. (a) Sustainable architecture diagram; (b) Traditional architecture of Iran diagram (Shahamat, H, 2014)

\section{Methodology}

The method in this article consists of two sections based on descriptive methods and field studies along with a comparative approach. In the first section, library-based studies and documentation review are the main sources for expressing, analyzing, describing, and interpreting the materials in this article. This type of research allows researchers to interact with the research question. The second section contains a comparative analysis of the library-based findings in the first part with field studies and analyzes the circumstances leading to the results in this study.

\subsection{Research Hypothesis}

According to preliminary studies and an examination of library-based documents as well asattention to different views of Iran architectural structures, this study's hypothesis is based on the grounds that the use of Culture, Politics, The principles of Iranian architecture and Civil rights with slight changes can be used in the structure of contemporary architecture in order to achieve sustainable architecture. By identifying and properly exploring the patterns and principles of past architecture and its proper combination with contemporary architecture, sustainable architecture and architecture with its ownidentity can be achieved.

\section{Results and Discussions}

At first should be said: difference between people's homes and a house designed by architect could give us overview of the needs, values and demands of the people. The modern man has own legend yet and Although shape of the houses are different in detail, but they may be the result of motivations and tendencies Which are not entity differences with the nature of thoughts the past, and this tendencies would always be socio-cultural(Rapoport A, 2008). actually is essential need to provide minimal requirements in conditions of comfort to every man. This minimum are includes common places for every type of culture and society.

In addition one of the most important parameters is considered more than anything else in the house issue cost. Building Usually, is faced with personal investment limited and also maximum result are achieved with consider the cost and try to make the minimum cost. With considering this issue, if to be prepared the instructions and guidelines design rules and regulations by architectural experts will be making great help for more efficiency make houses. For example, in a study of Dr Rezvani(2015), the fifth factor known as the "Politics", introduced as the another factor for sustainable development in the developing countries and emphasis the rich history of cultural and civilizational countries like Iran(Rezvani A, 2014). 


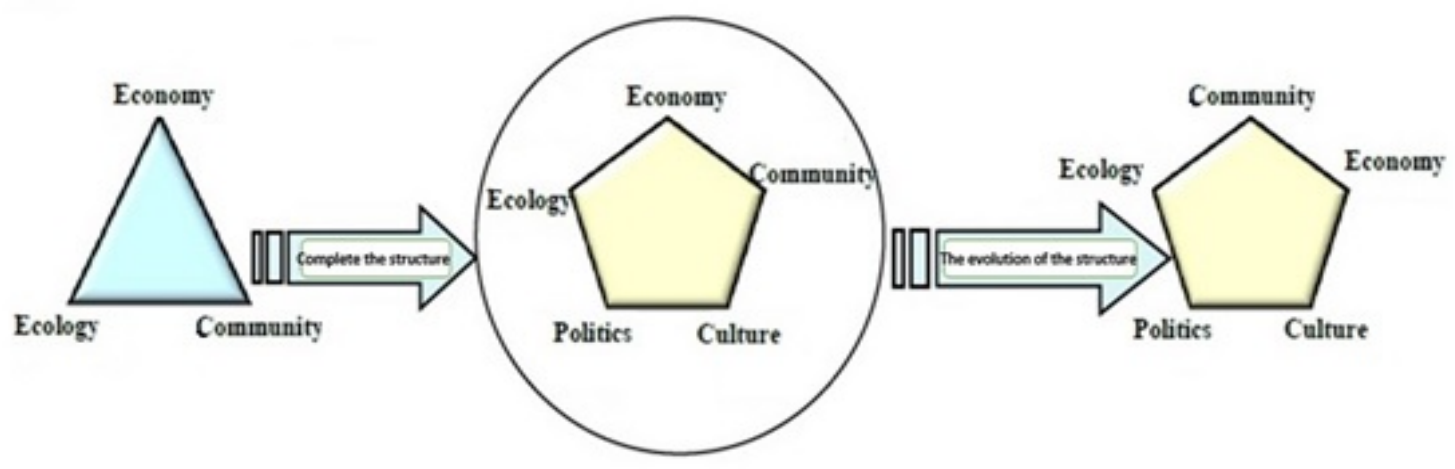

Figure 4. The proposed model for sustainable development in the developing world(Rezvani A, 2014)

\subsection{Review of Standards in the Pattern of Housing in Iran}

In this direction considered two essential issues as history of Iranian architecture and families culture and tastes of arrangement of furniture. Iranian artists and architects in the history for instead several unique historical monuments are worthy respect and appreciation. This works and especially homes that were built in different historical periods formed changes which have been derived from the specific needs people at different times, but these changes in recent decades has not been the origin of conscious and logical and by imitation have gone to the destination concerned(Shaykh Z, 2005). During the Qajar appear various architectural styles that tends to increase the extroversion in residential units(Etesam I, 1998). Also in the first decade of the fourteenth century(Solar calendar) onward Iranian architecture and with it quality of residential houses have been transformed by returning of architects who studied abroad(Hakim N, 1995).

The other hand human habitation is better to protect against weather conditions and create an environment. Essential air in the living environment, is including enough light moving oxygen, heat, humidity and enough light. An important factor are includes: the housing location in a vision and collection arrangement spaces inside the house and the structure. Also to achieve the ecological feels, need something includes a building insulated with windows fit to furnitureheat and ventilation adequate. As well composed the residential unit as an a collection of small social by specific components. That this components are divided into two general groups of people and furniture. Arrangement of home furniture, describe the internal emotions, mode of thinking, economic situation and social status of family members, because every man loves wants to change the built environment around and compatible environment with the emotions and Style(Fateh M, Darius B, 2011). This different tastes and variety production variety patterns which according to Iranian culture and society in three categories: traditional pattern, west pattern and composition pattern.

\subsection{Traditional Pattern}

In traditional house base organizing framework is Pymvn in the form of large, small and petty Pymvn that architects has been used. With relying on the system, the highest duty of architecture is cognitive, visual perception of space, inertial and current forces in framework building porter and was determined knowing that the design of the building, proportions and dimensions of loaded and empty building(Abolghasem S, Kiani M, 1987). Versatility is the pattern characteristic of spaces and furniture elements is not defining user environment. Because the middle of space is empty and just covered with carpet. For example, by inserting a Tablecloths Converter to dining room and by inserting a bed Converter to bedroom. In this model, the flexibility has high quality because the space is responding the majority of users needs. 


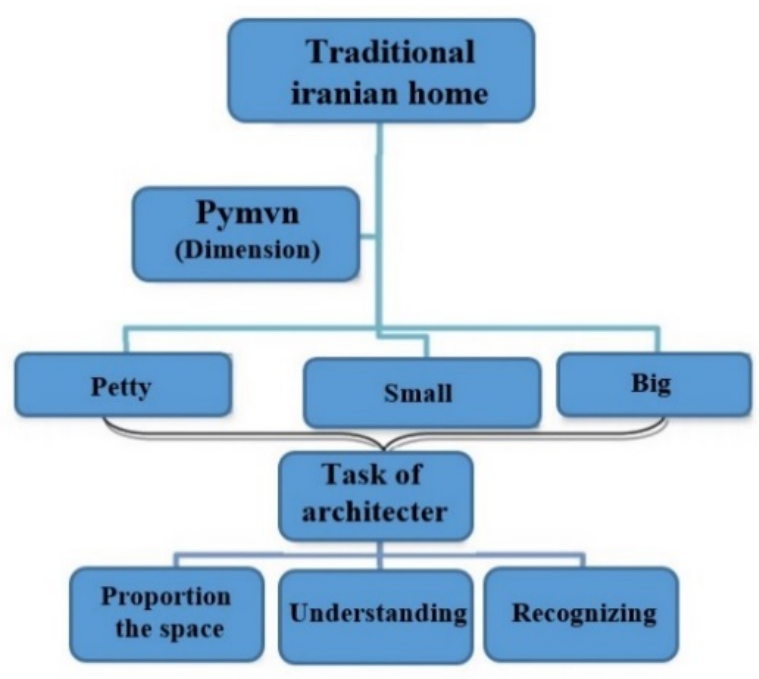

Figure 5. According to Iranian Pymvn in the design and patterns by the architect(Mirzazadeh nyarq M, Bemaniyan $\mathrm{M}, 2015)$

\subsection{West Pattern}

In this model, furniture elements of defining the user. This method comprehensive model of European furniture and tried by using a variety privacy of furniture be created in each space for various activities. In this model is partly reduced., the flexibility with regard to the Style of arrangement and quality space formed by of the home owner.

\subsection{Composition Pattern}

This pattern is obtained by combining of west and traditional pattern. This means that the elements and west furniture combines with traditional elements like rugs used with traditional arrangement. That is furniture without observance of privacy nearest to the wall and the vacant central space, in other words, a combination of west furniture and traditional physical pattern. In this model, flexibility is more prominent than west pattern.

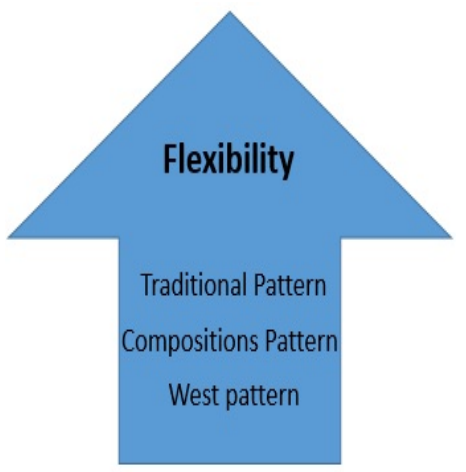

Figure 6. Amount of flexibility in terms of priority in housing design patterns (Source: authors) 

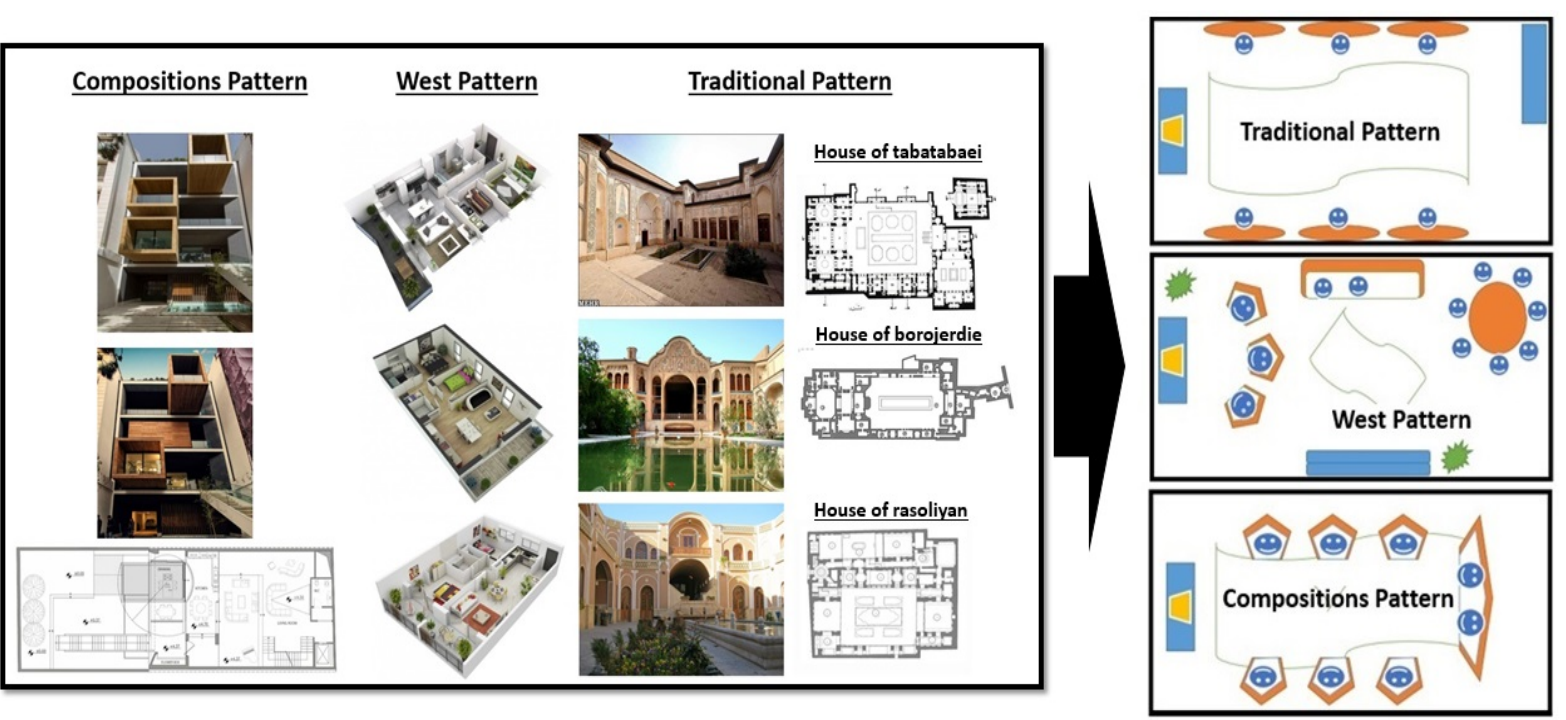

Figure 7. Flexible patterns in Iranian Housing (Source: authors)

\section{Conclusions}

Standard favorable of sustainable housing is not limited to shelter and protect man against bad weather and harm of animals and maybe is harm human beings, or be low cost or appropriate. All these are necessary but not sufficient, and all the issues does not cover have to be addressed that define the Favorable and sustainable housing. One of the essential and very important is that the housing must provide the location and atmosphere of peace, comfort and residence.

Providing this calm and comfort in close contact with cultural and settlement patterns of housing. These patterns are in three categories: traditional, west and combination pattern, in terms of cultural characteristics of each family in Iran. On the other hand need to review of the laws and regulations of the construction for out of the current difficulties are prerequisites for sustainable architecture in this country. According authors believe that considering the following graph can be achieved sustainable design patterns.

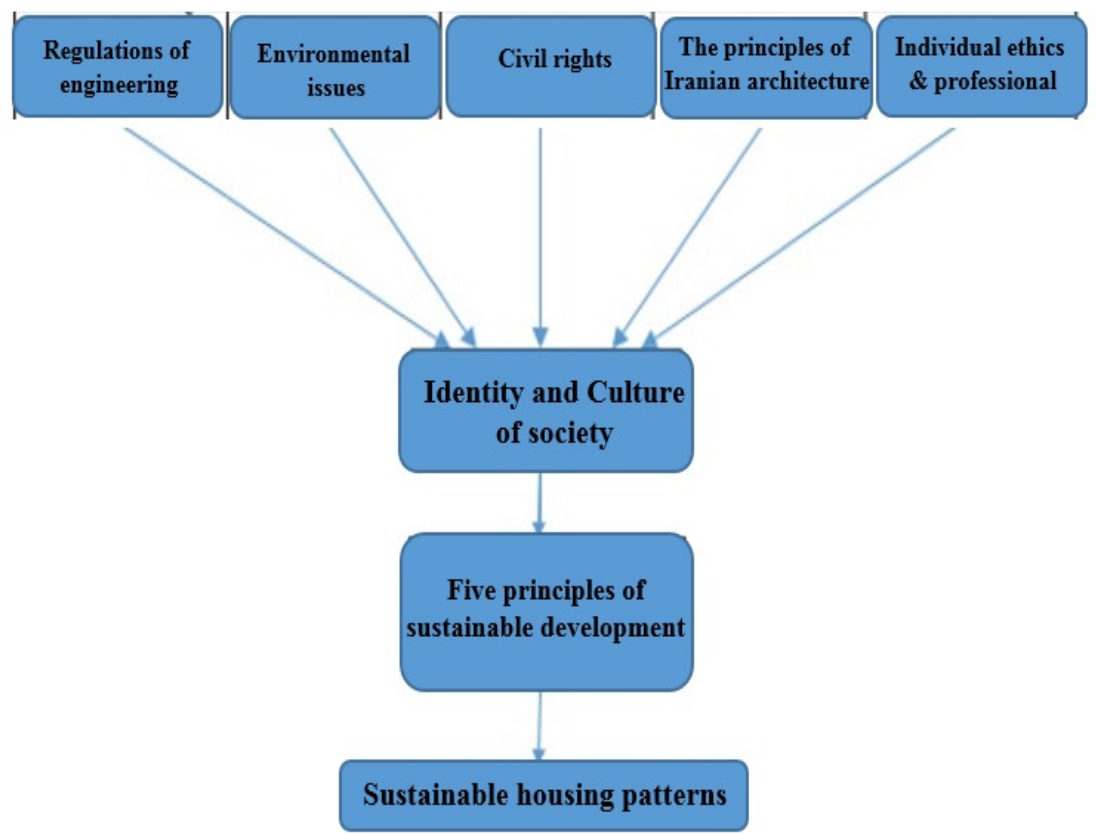

Figure 8. Steps to achieve sustainable housing design pattern in Iran (Source: authors) 


\section{Acknowledgment}

Thanks to the efforts of dear Sir DR. Alireza Rezvani who always his thoughts and presence is our guide.

\section{References}

Abd, R., \& Arkam Che Munaaim, M. (2013). Sustainable House in Iran's Desert.

Abolghasem, S., \& Kiani, M. (1987). Formative norm in Islamic architecture in Iran under the Islamic architecture. SID press, pp.77.

Alaraji, K. H., \& Mohd Jusan, M. (2014). Assessment of Perceived Flexibility in House Design using Conjoint Analysis (CA). International Journal of Applied Engineering Research, 9(14), 2473-2486.

Choguill, C. L. (2007). The search for policies to support sustainable housing. Habitat International, 31, 143-149. https://doi.org/10.1016/j.habitatint.2006.12.001

Edwards, B., \& Torrent, D. (2015). Sustainable housing, principles and implementation (2nd ed.). Parham role press, Pp.6-18-21-38.

Etesam, I. (1998). Study of Contemporary Iranian Architecture Europe, Proceedings of the Congress Architectural History Citadel of Bam, Tehran, Cultural heritage organization.

Fateh, M., \& Darius, B. (2011). Theoretical foundations of architecture (3rd ed.). Science and knowledge press, pp. 197.

Geertz, C. (1973). The Interpretation of Cultures: Selected Essays. Basic: New York, NY, USA.

Hakim, N. (1995). Iranian house architectural transformations in the first decades of the century. Architecture journal, 17.

Johnston, P. et al (2007). Reclaiming the Definition of Sustainability. Env Sci Pollut Res, 14(1), 60-66. https://doi.org/10.1065/espr2007.01.375

Kasmae, M. (2003). climate \& architecture ( $2^{\text {nd }}$ ed.). (M. Ahmadinezhad, Ed.). Khak, Isfahan, Iran. Pp.42-48.

Lawson, B. (2004). What designers know (1st ed.). Elsevier.

Mahdavinejad, M. et al. (2011). Role of LSF technology in economic housing for urban sustainability, case of Iran, Procedia Engineering, 21, Pp.2-7. https://doi.org/10.1016/j.proeng.2011.11.1980

Mahmoudi, M., Simchi, A., Imani, M., Milani, A. S., \& Stroeve, P. (2008). In Vivo MRI Detection of Gliomas by Chlorotoxin-Conjugated Superparamagnetic Nanoprobes. J. Phys. Chem, 112, Pp.14470-14481. https://doi.org/10.1021/jp803016n

Mirzazadeh nyarq, M., \& Bemaniyan, M. (2015). flexible design in residential homes, National conference on civil engineering and architecture with focus on sustainable development.

Molanaei, S., \& Soleimani, S. (2016). Insight into the valuable elements of Sistan local architecture in relation to climatic factors of sustainable architecture, The Scientific Journal of NAZAR research center (Nrc) for Art. Architecture \& Urbanism, 13(41), 63-74.

Nazirah, Z. A. (2005). Delivering sustainability through value management: the concet and performance overview. Engineering Construction and Architectural Management, Pp.168-180.

Pirnes, E. (2010). Cultural Policy in the sectoral trap-But how to escape it. Nord. Kult. Tidskr, 2, Pp.155-174.

Pirnia, M. (2005). Iranian Architecture Stylistics (G. Memarian, Ed.). Saadi. Tehran, Iran, Pp.26-38.

Proposed Modifications, 2012, Submission Plan Incorporating PreSubmission Draft, Chapter 3- ACHIEVING A SUSTAINABLE PATTERN OF DEVELOPMENT West Dorset District Council and Weymouth and Portland Borough Council.

Rapoport, A., 2008, Anthropology housing, Translation by khosrow Afzlyan, Second Edition, Ktabkadeh kasra press,pp.84-197.

Rezvani, A. (2014). Musavi, H. Five-axis model in sustainable development strategy, National conference on environment and sustainable development.

Samari, M., Ghodrati, N., Olfat, P., \& Shafiei, M. W. M. (2012). Investigation of sustainable development in residential building in Penang Island. International Journal of Emerging Trends In Engineering and Development, 7(2), 9 .

Sargazi, M. A. (2014). Sustainable Development and its Concepts in Rural Residential Spaces of Sistan, Iran. 
European Online Journal of Natural and Social Sciences, 3(4), 98-106.

Schneider, T., \& Till, J. (2005). Flexible Housing: The Means to the End.

Shahamat, H. (2014). Formal Sustainability in Traditional Architecture of Iran According To Five Principles of Traditional Architecture of Iran. J. Appl. Environ. Biol. Sci., 4(1), 100-110.

Shaykh, Z. (2005). Compared to traditional architecture and modern (home). Supervisor: Mohammad Sadiq F, Master's thesis Anthropology, pp.34.

Soini, K., \& Dessein, J. (2016). Culture-Sustainability Relation: Towards a Conceptual Framework. Sustainability, 8 , 167. https://doi.org/10.3390/su8020167

United Nations Human Settlements Programme. State of the world cities 2006/7. London: Earthscan.

United Nations. International covenant on economic, social and cultural rights; 16 December 1966. www.unhchr.ch/html/menu3/b/a_cescr.htmS, Accessed 10.07.14.

United Nations. United Nations millennium summit; 2000. www.un.org/millennium/decleration/ area552e.pdfS. Accessed 12.07.14.

United Nations. Universal declaration of human rights; 10 December 1948. www.un.org/overview/rights. htmlS. Accessed 14.07.14.

Veldhuisen, K. J., Thijssen, A. P., \& Timmermans, H. J. P. (1987). Flexibility in Architectural Design.

Williams, R. (1985). Keywords. A Vocabulary of Culture and Society. Oxford University Press: Oxford, UK.

\section{Copyrights}

Copyright for this article is retained by the author(s), with first publication rights granted to the journal.

This is an open-access article distributed under the terms and conditions of the Creative Commons Attribution license (http://creativecommons.org/licenses/by/4.0/). 